\title{
ChemComm
}

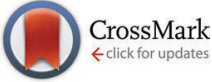

Cite this: Chem. Commun., 2015, 51, 3151

Received 16th December 2014, Accepted 9th January 2015

DOI: $10.1039 / c 4 c c 10014 j$

www.rsc.org/chemcomm

\section{Cytotoxic activity and protein binding through an unusual oxidative mechanism by an iridium(ı)-NHC complex $\dagger$}

\author{
Y. Gothe, ${ }^{a}$ T. Marzo, ${ }^{b}$ L. Messori ${ }^{b}$ and N. Metzler-Nolte ${ }^{\star^{a}}$
}

\begin{abstract}
A new NHC iridium(1) complex (1) showing significant antiproliferative properties in vitro is described here. Its crystal structure, solution behaviour and interactions with the model proteins cytochrome c (cyt c) and lysozyme were investigated. High resolution ESI-MS measurements suggest that this iridium(l) complex acts as a prodrug and binds cyt $c$ tightly through an unusual "oxidative" mechanism. Eventually, an iridium(III)-NHC fragment is found associated to the protein.
\end{abstract}

N-heterocyclic carbene (NHC) metal complexes have received increasing attention within the "Metals in Medicine" scientific community for their attractive biomedical properties. For instance, several metal-carbene complexes exhibiting promising antiproliferative effects were prepared and characterised in recent years. ${ }^{1-7}$ Especially, numerous gold(I)-NHC complexes were investigated and shown to be active against various cancer cell lines. ${ }^{8-11}$ The mode of action of this class of metal complexes is still debated although there is quite a large consensus that mitochondrial damage is a common and crucial feature of their biological activity, in particular in the case of Au-NHC derivatives.

An interesting, yet rather poorly investigated element for preparing new medicinally relevant metallocarbene complexes is iridium. Iridium recently received increased attention in its oxidation state + III as numerous iridium(III) complexes not only showed strong luminescence, but also manifested encouraging antiproliferative properties both in vitro and in vivo. ${ }^{12-15}$ In contrast, far less attention has been paid to iridium(I) complexes for medicinal uses, possibly due to the assumed lower stability of this oxidation state. An appreciable number of iridium(I)-NHC complexes is however studied for applications in homogeneous catalysis.

\footnotetext{
${ }^{a}$ Inorganic Chemistry I - Bioinorganic Chemistry, Faculty of Chemistry and Biochemistry, Ruhr-University Bochum, Universitätsstrasse 150, 44801 Bochum, Germany. E-mail: nils.metzler-nolte@rub.de; Web: www.chemie.rub.de/ac1

${ }^{b}$ Department of Chemistry, University of Florence, Via della Lastruccia 3, 50019 Sesto Fiorentino, Italy

$\dagger$ Electronic supplementary information (ESI) available: Experimental procedure, NMR data, and crystallographic data for $\mathbf{1}$; UV/vis studies, details on cell biology and mass spectrometry experiments. CCDC 1031569. For ESI and crystallographic data in CIF or other electronic format see DOI: $10.1039 / \mathrm{c} 4 \mathrm{cc} 10014 \mathrm{j}$
}

These iridium(I) complexes are characterized by a kinetically inert bonding of the NHC ligand and by favourable redox properties, with iridium switching between the oxidation states $+\mathrm{I}$ and $+\mathrm{III}$ in the elementary steps of these catalytic reactions. Although such properties have encouraged consideration of $\operatorname{Ir}(\mathrm{I})$ derivatives in other applications, only very few iridium(I) compounds were considered to the present date for medicinal uses, for example for antibacterial, antiparasitic and anticancer properties. ${ }^{16-18}$ The accumulation of Ir(I)-NHC complexes with charged side chains in cancer cells has been reported, ${ }^{18}$ but further biological investigations on iridium(I) compounds remain extremely rare. To the best of our knowledge, no studies concerning the interactions of iridium(I) compounds with proteins have ever been reported. We hypothesized that a change in its redox state might be relevant for the antiproliferative activity of Ir(I) complexes; accordingly, relying on the demonstrated stability of the Ir-NHC fragment, we choose to investigate such complexes for their antiproliferative activity and for their protein interactions.

Here, we describe the synthesis and characterisation of a new NHC-Ir(I) complex, namely [1-methyl-3-(pentamethylbenzyl)imidazol-2-ylidene] iridium(I) cyclooctadiene chloride 1, which has been studied as a prototype for iridium(I)-based metallodrugs. Compound $\mathbf{1}$ was chosen because it provides good stability and sufficient lipophilicity. The synthesis of this NHC iridium(I) complex was accomplished in three steps. First, the imidazolium salt precursor was synthesised by reacting 1 -(chloromethyl)-2,3,4,5,6-pentamethylbenzene with 1-methylimidazole. This imidazolium salt was then treated with $\mathrm{Ag}_{2} \mathrm{O}$ to generate the respective silver(I) carbene in situ. Afterwards, addition of $[\operatorname{Ir}(\mathrm{COD}) \mathrm{Cl}]_{2}$ led to the corresponding iridium(I) carbene 1 (Scheme 1).

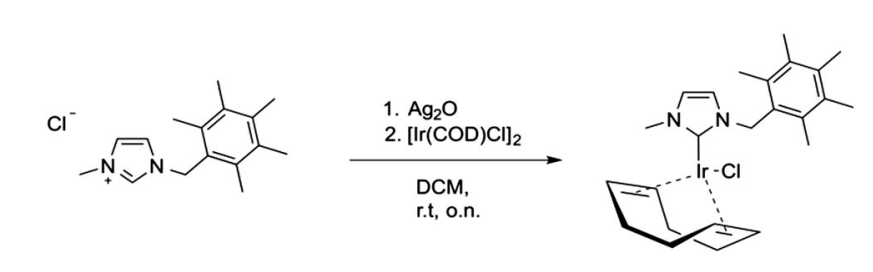

Scheme 1 Synthesis of the Ir-NHC complex 1. 


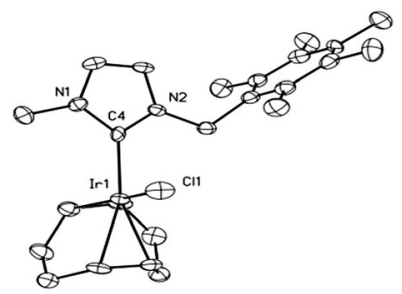

Fig. 1 Molecular structure of 1 . The heavy atoms are displayed at 50\% probability, hydrogen atoms were omitted for clarity. Selected bond lengths (Å) and angles (deg): Ir-C4, 2.035(7); Ir-Cl, 2.370(2); Ir-C17, 2.107(7); Ir-C18, 2.114(6); Ir-C21, 2.185(7); Ir-C22, 2.191(7); N1-C4, 1.379(8); N2-C4, 1.362(8); C4-Ir-Cl, 88.7(2); C4-Ir-C17, 94.5(3); C4-Ir-C18, 89.7(3); C4-Ir-C21, 159.0(2); C4-Ir-C22, 163.6(3); N1-C4-N2, 102.7(5).

Complex 1 was characterised by NMR, ESI-MS and elemental analysis, confirming the identity and purity of the compound. Single crystals suitable for X-ray diffraction were obtained by slow evaporation of a dichloromethane solution $¥$ (see Fig. 1).

This compound crystallises in the triclinic space group $P \overline{1}$ and shows the expected square-planar coordination of the iridium centre. The bond distances for Ir-C4 and $\mathrm{Ir}-\mathrm{Cl}$ (2.035(7) and 2.370(2) A, respectively) compare well with those observed in other $[\operatorname{Ir}(\mathrm{COD}) \mathrm{Cl}(\mathrm{NHC})]$ complexes. ${ }^{19,20}$

To assess the stability of this low-valent Ir complex, a solution of 1 in a mixed DMSO-ammonium acetate buffer (pH 6.8, with 50\% DMSO due to poor water solubility) with a final concentration of $200 \mu \mathrm{M}$ was analysed by time-dependent UV/Vis absorption spectroscopy. The changes in the spectral profile of 1 were monitored over $48 \mathrm{~h}$ at room temperature. Notably, the UV/Vis spectrum of 1 shows five intense absorption bands at 379, 409, 421, 469 and $485 \mathrm{~nm}$ characteristic of the iridium(I) center (see Fig. S2 in the ESI $\dagger$ ). The complex possesses a good stability in neat DMSO at $48 \mathrm{~h}$ but lower stability in the mixed solvent. The observed spectral changes consisting of the progressive decrease in intensity of the five bands up to their disappearance may be interpreted in terms of slow oxidation of $\operatorname{Ir}(\mathrm{I})$ to $\operatorname{Ir}(\mathrm{III})$, possibly caused by dioxygen. To confirm this hypothesis, the experiment was repeated upon addition of 10 eq. of hydrogen peroxide (see Fig. S4, ESI $\dagger$ ); under these latter conditions, a very fast decrease in intensity of all bands was again observed, confirming the redox nature of the observed spectral changes. Likewise, if the time-dependent UV/Vis experiment is performed in a glove box with rigorous exclusion of dioxygen (and other oxidants), the Ir(I) complex remains unchanged over $18 \mathrm{~h}$. If the cuvette is subsequently opened up to air outside the glove box, decomposition occurs within a few hours (Fig. S5, ESI $\dagger$ ).

The antiproliferative activity of 1 towards the cancer cell lines MCF-7 (human breast adenocarcinoma) HT-29 (colon adenocarcinoma) and HEK-293T cells (human embryonic kidney) was determined by the MTT assay. The iridium complex 1 exhibits a moderate yet appreciable cytotoxicity against all three tested cell lines with similar $\mathrm{IC}_{50}$ values ranging from $14.6 \mu \mathrm{M}$ to $19.3 \mu \mathrm{M}$ (Table 1 ).

To gain a more detailed insight into the antiproliferative effects of complex 1, the growth of HEK-293T cells under treatment with 1 was analysed. For this purpose, we used the xCELLigence RTCA (Real Time Cell Analyser) system, which monitors the cellular impedance of adherent HEK-293T cells before (24 h) and during
Table $1 \quad I C_{50}$ values in $\mu M$ of 1 for the antiproliferative effects in MCF-7, HT-29 and HEK-293T cells. ${ }^{a}$ The incubation time was $48 \mathrm{~h}$, mean value \pm s.d. are from three independent experiments

\begin{tabular}{lccr}
\hline Cell line & MCF-7 & HT-29 & HEK-293T \\
\hline 1 & $14.6 \pm 2.5$ & $19.3 \pm 3.8$ & $16.1 \pm 6.4$ \\
${ }^{a}$ Examples of dose-response curves are provided in the ESI.
\end{tabular}

treatment with $\mathbf{1}$ (additional $72 \mathrm{~h}$ ). The measured impedance of the cell is proportional to the total area of tissue-culture, displayed as a dimensionless parameter termed cell index. Control cells with $0.5 \%$ DMSO were monitored in parallel. Fig. 2 shows the time-dependent cell growth of the HEK-293T cells under this treatment regime.

Depending on the applied concentration of complex 1 , different cell growth profiles were observed. Whereas the treatment with $10 \mu \mathrm{M}$ has just a minor influence on the cell growth, treatment with a concentration of $20 \mu \mathrm{M}$ leads to significant growth inhibition, which is in accordance with the $\mathrm{IC}_{50}$ values. Full inhibition of cell growth is reached by a $30 \mu \mathrm{M}$ treatment.

As shown above, the iridium(I) complex causes acceptable in vitro cell growth inhibition effects on three representative cell lines. To elucidate molecular mechanism of action of new anti-cancer metallodrugs, the identification of their possible biological targets is an issue of crucial importance. Indeed, interactions with proteins seem to play a key role in the mode of action of many anti-cancer metallodrugs. ${ }^{21}$

With this in mind, we investigated the reactions of our new NHC iridium(I) complex 1 with two model proteins, namely horse heart cytochrome $c$ and hen egg white lysozyme. High-resolution electrospray ionisation mass spectrometry (HR-ESI-MS) is a powerful analytical tool which enables the identification and characterisation of the resulting metallodrug-protein adducts. Solutions of 1 were incubated with the protein at $37{ }^{\circ} \mathrm{C}$. At selected time points $(24 \mathrm{~h}$, $48 \mathrm{~h}, 72 \mathrm{~h}$ ), aliquots were taken and analyzed on a high-resolution mass spectrometer after electrospray ionization. Notably, several adducts are formed in the reaction of $\mathbf{1}$ with cytochrome $c$, whereas the intensity of peaks from adducts formed between lysozyme and 1 is too low to be characterised. The resulting ESI-MS spectrum of cytochrome $c$ after treatment with $\mathbf{1}$ is shown in Fig. 3.

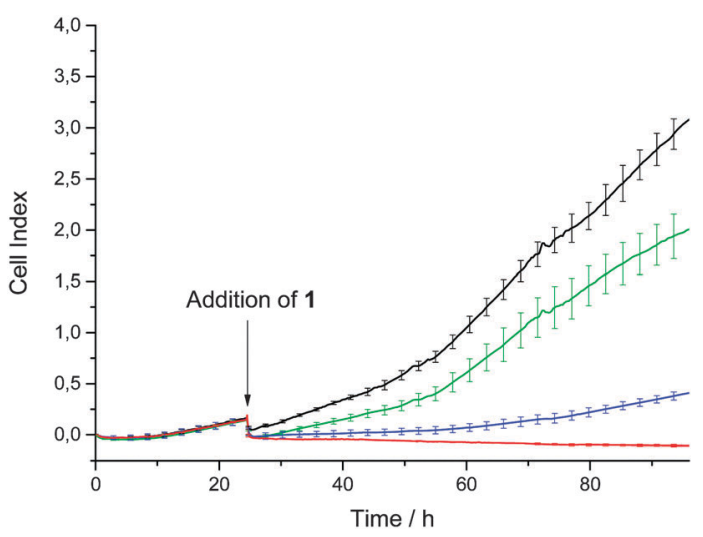

Fig. 2 Time dependent cell growth of HEK-293T cells after treatment with 1 with $0.5 \%$ DMSO only (black line), and $10 \mu \mathrm{M}$ (green line), $20 \mu \mathrm{M}$ (blue line) and $30 \mu \mathrm{M}$ (red line) 1 , respectively. 


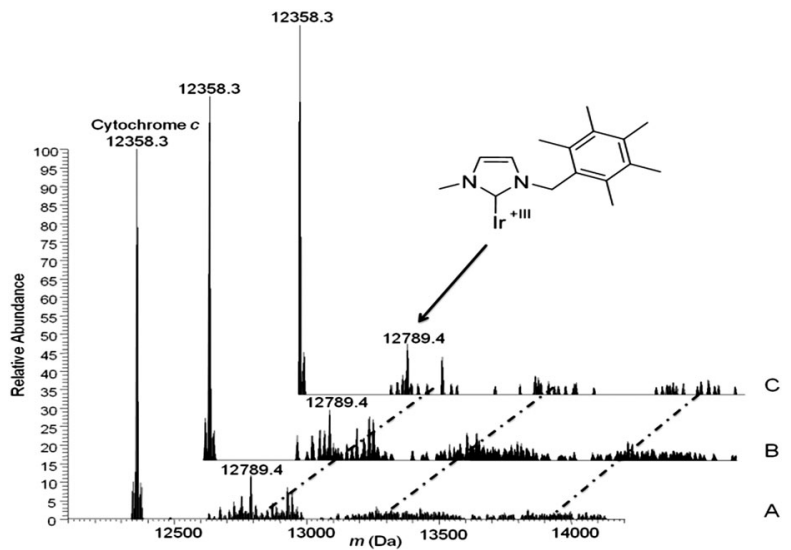

Fig. 3 HR-ESI-MS of cytochrome $c$ treated with $100 \mu \mathrm{M}$ of 1 (complex/ protein $=10: 1)$ in $20 \mu \mathrm{M}$ ammonium acetate buffer, $\mathrm{pH} 6.8$ recorded after $24 \mathrm{~h}(\mathrm{~A}), 48 \mathrm{~h}(\mathrm{~B})$, and $72 \mathrm{~h}(\mathrm{C})$ of incubation at RT.

Within the large number of adducts formed in the reaction of 1 with cyt $c$, the most abundant peak at 12789.4 Da can be straightforwardly assigned to cyt $c$ bound to an iridium-NHC fragment while chloride and cyclooctadiene ligands are fully detached. The adduct assignment was further supported by direct comparison of the observed and calculated isotope patterns, which matched quite well. In addition, based on the calculated net charge, we can deduce that protein-bound iridium has undergone oxidation from Ir(I) to $\operatorname{Ir}($ III). These observations imply that the loss of the more labile ligands together with oxidation of the iridium center clear the way for strong binding of kinetically inert $\operatorname{Ir}($ III) to cytochrome $c$. This kind of protein binding is reminiscent of the mode of binding of the aquopentammineruthenium(II) complex to ferrocytochrome $\mathrm{c}$ described by Gray and coworkers some time ago. ${ }^{21}$ In the latter case too, a kinetically more labile ruthenium(II) species first binds the protein upon replacement of the weak aqua ligand with imidazole, then ruthenium(II) undergoes oxidation to the more inert ruthenium(III) and as such remains firmly bound to the protein. Accordingly, the cytotoxic properties of the tested iridium(I)-NHC species might well result from protein coordination of an iridium(I) fragment and subsequent oxidation to kinetically inert iridium(III)-protein adducts, with associated loss of protein function.

In conclusion we have prepared and fully characterised here a new iridium(I)-NHC complex and determined its single crystal $\mathrm{X}$-ray structure. The complex shows significant antiproliferative effects in the low $\mu \mathrm{M}$ range against three different cancer cell lines. In time-dependent cell growth experiments, full inhibition of HEK-293T cell growth was achieved at a concentration of $30 \mu \mathrm{M}$. Notably, this is the first work reporting the reactivity of a cytotoxic iridium(I)-NHC (1) complex with proteins. The main adduct, formed in the reaction between cytochrome $c$ and $\mathbf{1}$, results from protein binding of a stable iridium-carbene fragment with concurring loss of chlorido and cyclooctadiene ligands as well as simultaneous oxidation of $\operatorname{Ir}(\mathrm{I})$ to $\operatorname{Ir}(\mathrm{III})$. Overall, these observations feature a peculiar mechanism of iridium binding to this model protein accompanied by oxidation to inert iridium(III) ("oxidative protein binding”). Although such a protein binding mechanism has been reported before by Gray and coworkers, ${ }^{21}$ it has so far never been associated with anti-proliferative activity of metal complexes. Such a mechanism might be further exploited for selective modification of proteins and for tight anchoring of metal-attached carbene groups. Thus, it is reasonable to assume that this class of iridium(I) complexes has the potential of metalating and altering a variety of biologically relevant cellular proteins, ultimately leading to irreversible cell damage and death.

Y. G. thanks Lara Massai for help with the UV/Vis measurements as well as Elena Michelucci for measurements and simulations of the ESI-MS spectra. The help of Klaus Merz with the crystal structure refinement and of Sandra Bobersky for the introduction to the Xcelligence system is gratefully acknowledged. The authors also gratefully acknowledge financial support of the COST action CM1105 (STSM to Y.G.), of Beneficentia Stiftung (Vaduz) and CIRCMSB (Bari, Italy); and by the Cluster of Excellence RESOLV (EXC 1069) funded by the Deutsche Forschungsgemeinschaft.

\section{Notes and references}

$\ddagger$ Crystallographic details were deposited as CCDC no. 1031569 .

1 F. Hackenberg and M. Tacke, Dalton Trans., 2011, 43, 8144-8153.

2 L. Oehninger, R. Rubbiani and I. Ott, Dalton Trans., 2013, 42, 3269-3284.

3 W. Liu and R. Gust, Chem. Soc. Rev., 2013, 42, 755-773.

4 G. Gasser, I. Ott and N. Metzler-Nolte, J. Med. Chem., 2011, 54, 3-25.

5 G. Gasser and N. Metzler-Nolte, Curr. Opin. Chem. Biol., 2012, 16, $84-91$.

6 T. Zou, C. T. Lum, C.-N. Lok, W.-P. To, K.-H. Low and C.-M. Che, Angew. Chem., Int. Ed., 2014, 23, 5810-5814.

7 A. John and P. Ghosh, Dalton Trans., 2010, 39, 7183-7206.

$8 \mathrm{~J}$. Lemke, A. Pinto, P. Niehoff, V. Vasylyeva and N. Metzler-Nolte, Dalton Trans., 2009, 7063-7070.

9 A. Gutiérrez, M. C. Gimeno, I. Marzo and N. Metzler-Nolte, Eur. J. Inorg. Chem., 2014, 2512-2519.

10 R. Rubbiani, E. Schuh, A. Meyer, J. Lemke, J. Wimberg, N. MetzlerNolte, F. Meyer, F. Mohr and I. Ott, Med. Chem. Commun., 2013, 4, 942-948.

11 R. Rubbiani, I. Kitanovic, H. Alborzinia, S. Can, A. Kitanovic, L. A. Onambele, M. Stefanopoulou, Y. Geldmacher, W. S. Sheldrick, G. Wolber, A. Prokop, S. Wölfl and I. Ott, J. Med. Chem., 2010, 53, 8608-8618.

12 K. K. W. Lo and K. Y. Zhang, RSC Adv., 2012, 2, 12069-12083.

13 Y. Geldmacher, M. Oleszak and W. S. Sheldrick, Inorg. Chim. Acta, 2012, 393, 84-102.

14 M. Graf, Y. Gothe, N. Metzler-Nolte, R. Czerwieniec and K. Sünkel, J. Organomet. Chem., 2014, 765, 46-52.

15 Z. Liu and P. J. Sadler, Acc. Chem. Res., 2014, 47(4), 1174-1185.

16 N. Falzone, L. Böhm, J. C. Swarts and C. E. J. Rensburg, Anticancer Res., 2006, 26, 147-152.

17 J. Rajput, J. R. Moss, A. T. Hutton, D. T. Hendricks, C. E. Arendse and C. Imrie, J. Organomet. Chem., 2004, 1553-1568.

18 P. V. Simpson, C. Schmidt, I. Ott, H. Bruhn and U. Schatzschneider, Eur. J. Inorg. Chem., 2013, 5547-5554.

19 A. G. Tennyson, E. L. Rosen, M. S. Collins, V. M. Lynch and C. W. Bielawski, Inorg. Chem., 2009, 48, 6924-6933.

20 S. Leuthäußer, D. Schwarz and H. Plenio, Chem. - Eur. J., 2007, 13, 7195-7203.

21 K. M. Yocom, J. B. Shelton, J. R. Shelton, W. A. Schroeder, G. Worosila, S. S. Isied, E. Bordignon and H. B. Gray, Proc. Natl. Acad. Sci. U. S. A., 1982, 79, 7052-7055. 